\title{
An Unusual Case of ACLF : First Report from Bangladesh
}

\author{
AYUB AL MAMUN, ${ }^{1}$ MAMUN-AL-MAHTAB,${ }^{1}$ ABU SALEH MOHAMMAD SADEQUL ISLAM, ${ }^{1}$ MOHAMMAD FORHAD \\ ABEDIN, ${ }^{1}$ DULAL CHANDRA SAHA, ${ }^{1}$ SHEIKH MOHAMMAD FAZLE AKBAR, ${ }^{2}$ SALIMUR RAHMAN ${ }^{1}$
}

\begin{abstract}
Background: Autoimmune hepatitis is often unrecognized and under-diagnosed, especially in our part. Acute on chronic liver failure (ACLF) on the other hand is a newly recognized disease entity describing patients who develop acute liver failure on the background of pre-existing chronic liver disease. Methods: We present an elderly lady who presented to us with history of episodic fever and jaundice over a period of two years. Results: Although initially diagnosed as a case of idiopathic thrombocytopenic pupura (ITP), on further investigation she was finally diagnosed as ACLF (hepatitis $B$ virus induced acute liver failure on autoimmune hepatitis induced cirrhosis of liver).
\end{abstract}

Keywords: ACLF; autoimmune hepatitis; hepatitis B virus; cirrhosis

\section{Introduction:}

Liver failure can develop either as acute liver failure in the absence of any pre-existing liver disease, an acute deterioration of known or unknown chronic liver disease, the ACLF, or as a chronic decompensation in an end-stage liver disease. Autoimmune hepatitis is a form of chronic liver disease of unknown aetiology with aberrant auto-reactivity and genetic predisposition. We present an elderly lady with ACLF, who was initially diagnosed as a case of idiopathic thrombocytopenic purpura (ITP), but subsequently found to have HBV induced acute liver failure on autoimmune hepatitis induced cirrhosis of liver.

\section{Case Report}

The first patient was a normotensive, non-diabetic 54 year old house wife coming from an upper middle class family. She presented with episodic fever for 2 years, yellow eyes and urine and abdominal distension for 3 months.

The patient stated that she was relatively alright 2 years back. She then developed fever which was intermittent associated with chills and rigor and redness of eye with reddish spots in different parts of the body, mostly on the thorax, buttock and lower limbs. Fever was high grade and highest recorded temperature was $103^{\circ} \mathrm{F}$, which subsided by taking anti-pyretics. She also had joint pain and swelling, mostly of large joints of both upper and lower limbs. She was diagnosed of having dengue fever at that time and managed conservatively.

1. Department of Hepatology, Bangabandhu Sheikh Mujib Medical University, Dhaka, Bangladesh

2. Department of Medical Sciences, Toshiba General Hospital, Tokyo, Japan

Correspondance : Dr. Mamun-Al-Mahtab, Associate Professor of Hepatology, Bangabandhu Sheikh Mujib Medical University, Dhaka, Bangladesh. E-mail: shwapnil@agni.com
She remained afebrile for 2 weeks following that episode, but developed similar fever and rash again and took antibiotics on this occasion. From this point onwards the fever took an episodic pattern with about 2 weeks symptom free periods followed by fever, joint pain and rash for about a week.

She consulted a Haematologist after suffering for about 5 months. She was diagnosed as a case of ITP and treated with prednisolone. She was better during the initial 3.5 moths, but returned to her usual pattern of illness then after. She received treatment with prednisolone and several units of blood transfusion over the subsequent months. However she never recovered completely; rather her illness deteriorated in terms of both duration and severity.

She eventually developed yellow colouration of eyes and urine, which was not associated with nausea, vomiting, itching or pale stool. However about a week later, gradual abdominal distension with low grade fever. There was no cough, breathlessness, alteration of bowel habit or urinary complaints. At this stage she was referred to us and a diagnosis was ultimately attained. The patient had no significant history of past illness.

On examination she was ill looking, of average built, mildly anaemic having marked jaundice and mild oedema. She had bruise on extensor surface of both upper limbs and hypopigmented areas on lips, centre of abdomen and both legs. She had fever, highest recorded temperature being $102^{0} \mathrm{~F}$.lood pressure was $110 / 70 \mathrm{~mm}$ of $\mathrm{Hg}$ and pulse $96 / \mathrm{min}$ and regular.

Her investigations revealed serum serum bilirubin $10.3 \mathrm{mg} /$ $\mathrm{dl}$, serum ALT $65 \mathrm{U} / \mathrm{L}$, serum alkaline phosphatase $112 \mathrm{U} / \mathrm{L}$, prothrombine time $25.3 \mathrm{sec}$ (control $12 \mathrm{sec}$ ), serum albumin $3.1 \mathrm{gm} / \mathrm{dl}$. She tested positive for ANA, HBsAg and HBeAg by ELISA. HBsAg was however negative by ELISA 4 months 
back. Anti HCV and anti-Sm antibody were also negative. HBV DNA was $2.8 \times 10^{9}$ copies/ml by PCR.

Her fasting blood sugar was $4.4 \mathrm{mmol} / \mathrm{L}$, haemoglobin 10.1 $\mathrm{gm} / \mathrm{dl}$, total count of WBC $8000 / \mathrm{cmm}$ (neutrophil $80 \%$, lymphocyte $14 \%$, eosinophil $2 \%$ and monocyte $4 \%$ ) and platelet count $90,000 / \mathrm{cmm}$. She had mild thrombocytopenia with normocytic anaemia in peripherl bolld film. Bone marrow study showed moderately hypercellular marrow with increased $\mathrm{M} / \mathrm{E}$ ratio. Erythropoiesis was active and normoblastic, granulopoiesis active, megakaryocytes adequate and mildly increased lymphocytes, plasma cells and histocytes. The findings were consistent with swecondary reactive marrow. Chest x-ray was normal, while ultrasonography of hepatobiliary system revealed small size liver with coarse echotexture, spleenomegaly and moderate ascites. Endoscopy of upper GIT showed grade I oesophageal varices and portal hypertensive gastropathy.

The diagnosis of ACLF i.e. HBV related acute liver failure on type I autoimmune hepatitis induced decompensated cirrhosis of liver was thus made.

\section{Discussion:}

ACLF is defined as acute hepatic insult manifesting as jaundice and coagulopathy, complicated within 4 weeks by ascites and/or encephalopathy in a patient with previously diagnosed or undiagnosed chronic liver disease. ${ }^{1}$

Decompensation of cirrhosis usually leads to irreversible deterioration where liver transplantation remains the only curative option. Both acute liver failure (ALF) and ACLF on the other hand result from acute insults that are potentially reversible. The reversibility however depends on severity and nature of the acute insult as well as on the degree of underlying chronic liver disease (CLD). The acute insults have geographic variation and include both infectious and non-infectious aetiologies. The major etiologic agents for ACLF are differ between East and West. In the West, alcohol and drugs are responsible for most acute insults, whereas infections predominate in the East.

Among the infectious etiologies, reactivation of hepatitis B virus infection is one of the major causes of ACLF in the Asian region ${ }^{2}$. This reactivation may be spontaneous or may be due to withdrawal of anti-virals or administration of immunosuppressive therapy, ${ }^{3}$ improvement of immune status after HAART therapy for HIV, ${ }^{4}$ anti-HBV drug induced viral resistance ${ }^{5}$ or reactivation of the occult $\mathrm{HBV}$ infection. ${ }^{6}$

Autoimmune hepatitis is characterized by female predominance, circulating auto-antibodies, hypergammaglobulinaemia and association with HLA DR3 and
HLA DR $4^{7}$. This entity was first described by Waldenstorm in $1950 .{ }^{8}$ It's aetiology remains unknown. There are three types of autoimmune hepatitis, namely type 1,2 and 3. Most patients with autoimmune hepatitis have type 1 disease characterized by anti-DNA and anti-smooth muscle antibodies. In type 2, there is association with anti-liver kidney microsomal (LKM) type 1 antibody. It is divided into types $2 \mathrm{a}$ and $2 \mathrm{~b}$. In type $2 \mathrm{a}$, liver kidney cytochrome monooxygenase P450 2D6 is the target antigen. ${ }^{9}$ It is associated with severe chronic hepatitis. Other antibodies are usually absent. Patients often have associated extra-hepatic immunemediated diseases like diabetes and show good response to corticosteroids. In type $2 \mathrm{~b}$ on the other hand, anti-LKM-1 antibody is present in upto $70 \%$ cases. There is association with chronic hepatitis $\mathrm{C}$ virus infection and these patients respond to anti-virals better than to immuno-suppressive treatment. This type shows a male predominance. Type 3 autoimmune hepatitis shows association with anti-soluble liver antigen (SLA) and anti-liver and pancreas antigen (LPA) antibodies. $^{10}$

Autoimmune hepatitis results from defect in suppressor $\mathrm{T}$ cells leading to production of antibodies against hepatocyte surface antigens. The nature of target antigens on hepatocytes is unknown. Liver histology in autoimmune hepatitis shows cellular infiltrates in zone 1 comprising mainly of lymphocytes and plasma cells. There is aggressive septa formation and steatosis in the liver. The condition rapidly progresses to macronodular cirrhosis, usually within two years. ${ }^{11}$ During remissions, although the disease remains inactive, restoration of normal hepatic architecture does not occur.

The condition characteristically has two peaks, once in prepubertal period and then again between $4^{\text {th }}$ to $6^{\text {th }}$ decades. Onset is insidious with patients complaining of feeling unwell and jaundice. In some the presentation may mimic acute viral hepatitis. Chronic autoimmune hepatitis may remain quiescent for years. Amenorrhoea is common. On examination vascular spiders are seen almost in every case. Acne, hirsutism and cutaneous striae are present. Patients usually have hepatomegaly. Extra-hepatic manifestations are common and include purpura, erythemas, arthralgia, lymphadenopathy, pulmonary infiltrates, pleurisy, rheumatic heart disease, ulcerative colitis, diabetes, thyroiditis, renal tubular defects and haemolytic anaemia. ${ }^{11}$ On investigation there is hyperbilirubinaemia, raised IgG, markedly elevated serum transaminases and pancytopenia. Liver biopsy remains an important tool for diagnosis.

Important differential diagnosis include chronic hepatitis B and C, Wilson's disease, drug induced hepatitis, alcoholic 
liver disease, non-alcoholic steatohepatitis and haemochromatosis. ${ }^{12}$

\section{Conclusion:}

ACLF is not infrequent, but careful clinical observation is needed to identify cases. It is very important as although the disease is potentially reversible, without appropriate measures the outcome may fatal.

\section{Conflict of Interest : None}

\section{References:}

1. Sarin SK, Kumar A, Almeida J, Chawla YK, Tao WC, Fan ST, Garg H, Silva HJ, Hamid S, Jalan R, Komolmitr P, Lau GK, Liu Q, Madan K, Mohamed R, Ning Q, Rahman S, Rastogi A, Riordan SM, Sakhuja P, Samuel D, Shah S, Sharma BC, Sharma P, Takikawa Y, Thapa BR, Yuen MF. Acute on chronic liver failure: consensus recommendations of the Asian pacific Association for the Study of the Liver (APASL). Hepatol Int 2008 (in press).

2. Kohrt HE, Ouyang DL, Keeffe EB Antiviral prophylaxis for chemotherapy-induced reactivation of chronic hepatitis B virus infection. Clin Liver Dis 2007;11:965-91.

3. Subfulminant hepatitis B after infliximab in Crohn's disease: need for HBV-screening? World J Gastroenterol 2006; 12:974-6.

4. Sheng WH, Kao JH, Chen PJ, Huang LM, Chang SY, Sun HY, Hung CC, Chen MY, Chang SC. Evolution of hepatitis
B serological markers in HIV-infected patients receiving highly active antiretroviral therapy. Clin Infect Dis 2007;45: 1221-9.

5. Chu CM, Liaw YF. Predictive factors for reactivation of hepatitis B following hepatitis B e antigen seroconversion in chronic hepatitis B. Gastroenterology 2007;133:1458-65.

6. Perceau G, Diris N, Estines O, Derancourt C, Lévy S, Bernard $\mathrm{P}$. Late lethal hepatitis $\mathrm{B}$ virus reactivation after rituximab treatment of low-grade cutaneous B-cell lymphoma. Br J Dermatol 2006;155:1053-6.

7. Obermayer-Straub P, Strassburg CP, Manns MP. Autoimmune hepatitis. J Hepatol 2000; 32 (1); 181.

8. Waldenstrom J. Leber, Bluproteine und Nahrungsweiss Stoffwechs Krh, Sonderband: XV, p 8. Tagung, Bad Kisingen, 1950.

9. Homberg JC, Abuaf N, Bernard O et. al. Chronic active hepatitis associated with antiliver/kidney microsome antibody type 1: a second type of 'autoimmune' hepatitis.

10. Wies I, Brunner S, Henninger J et. al. Identification of target antigen for SLA/LP autoantibodes in autoimmune hepatitis. Lancet 2000; 355:1510.

11. Read AE, Harrison CV, Sherlock S. 'Juvenile cirrhosis'; part of a systemic disease. The effect of corticosteroid therapy.

12. Sherlock S, Dooley J. Diseases of the Liver and Biliary System. $11^{\text {th }}$ Edition, 2002; Blackwell Science. 